\title{
Coral-like $\mathrm{Li}_{7} \mathrm{La}_{3} \mathrm{Zr}_{2} \mathrm{O}_{12}$ filled PVDF-HFP/LiODFB composite
}

electrolyte for solid-state batteries with excellent cycle performance Shengdong Tao ${ }^{\mathrm{a}}$, Jian $\mathrm{Li}^{\mathrm{a}, \mathrm{c}^{*}}$ Lihua Wang ${ }^{\mathrm{b} *}$, Weiguo Huanga ${ }^{\mathrm{a}}$, Minchao Zhang ${ }^{\mathrm{a}}$, Zhexi Chi ${ }^{\mathrm{a}}$, Shuohan Wanga ${ }^{\mathrm{a}}$, Yongzhi Chen ${ }^{\mathrm{b}}$, Lei Shang ${ }^{\mathrm{c}}$ ${ }^{a}$ School of Materials Science and Engineering, Central South University, Changsha, Hunan 410083, China $\square$

${ }^{b}$ College of Mechanical Engineering, Hunan Institute of Science and Technology, Yueyang 414006, China

cHunan Zhengyuan Institute for Energy Storage Materials and Devices, Changsha, Hunan 410083, China

*Corresponding author. Tel.: +86-731-82075517; Fax: +86-731-82075517. E-mail addresses: mitaer113@csu.edu.cn. (J. Li.),837728474@qq.com (L. Wang). 229339466@qq.com (Y.Chen).

\section{Supporting Information}

\section{S 1. Preparation of LLZO-B}

Total weight $25 \mathrm{~g}$ of $\mathrm{Li}_{2} \mathrm{CO}_{3}, \mathrm{La}_{2} \mathrm{O}_{3}$ and $\mathrm{ZrO}_{2}$ (the molar ratio of 8.4/3/4) were put in a $\mathrm{ZrO}_{2}$ tank by planetary ball mill $\left(400 \mathrm{r} \mathrm{min}^{-1}\right)$ for $12 \mathrm{~h}$. Then, the ball-milled material was calcinated at $550^{\circ} \mathrm{C}$ for $2 \mathrm{~h}$ and $1000^{\circ} \mathrm{C}$ for $6 \mathrm{~h}$ in air to obtain the LLZO-B materials.

\section{S 2. Preparation of LLZO-S}

Citric acid (25.2 mmol) was dissolve in a mixed solvent of ethanol $(50 \mathrm{ml})$ and deionized water $(30 \mathrm{ml})$. Next, $25.2 \mathrm{mmol} \mathrm{LiAc}, 9 \mathrm{mmol} \mathrm{La}\left(\mathrm{NO}_{3}\right)_{3}$ and $6 \mathrm{mmol}$ $\mathrm{Zr}\left(\mathrm{NO}_{3}\right)_{4}$ were added into the mixed solution and stirred continuously to obtain a jelly- 
like gel. Then the gel is heated at $60{ }^{\circ} \mathrm{C}$ by a water bath under stirred continuously to obtain a dry gel, and it is dried in an oven at $120^{\circ} \mathrm{C}$ for $12 \mathrm{~h}$. Finally, the dry gel was calcinated at $550{ }^{\circ} \mathrm{C}$ for $2 \mathrm{~h}$ and $1000{ }^{\circ} \mathrm{C}$ for $6 \mathrm{~h}$ in air to obtain the LLZO-S materials.

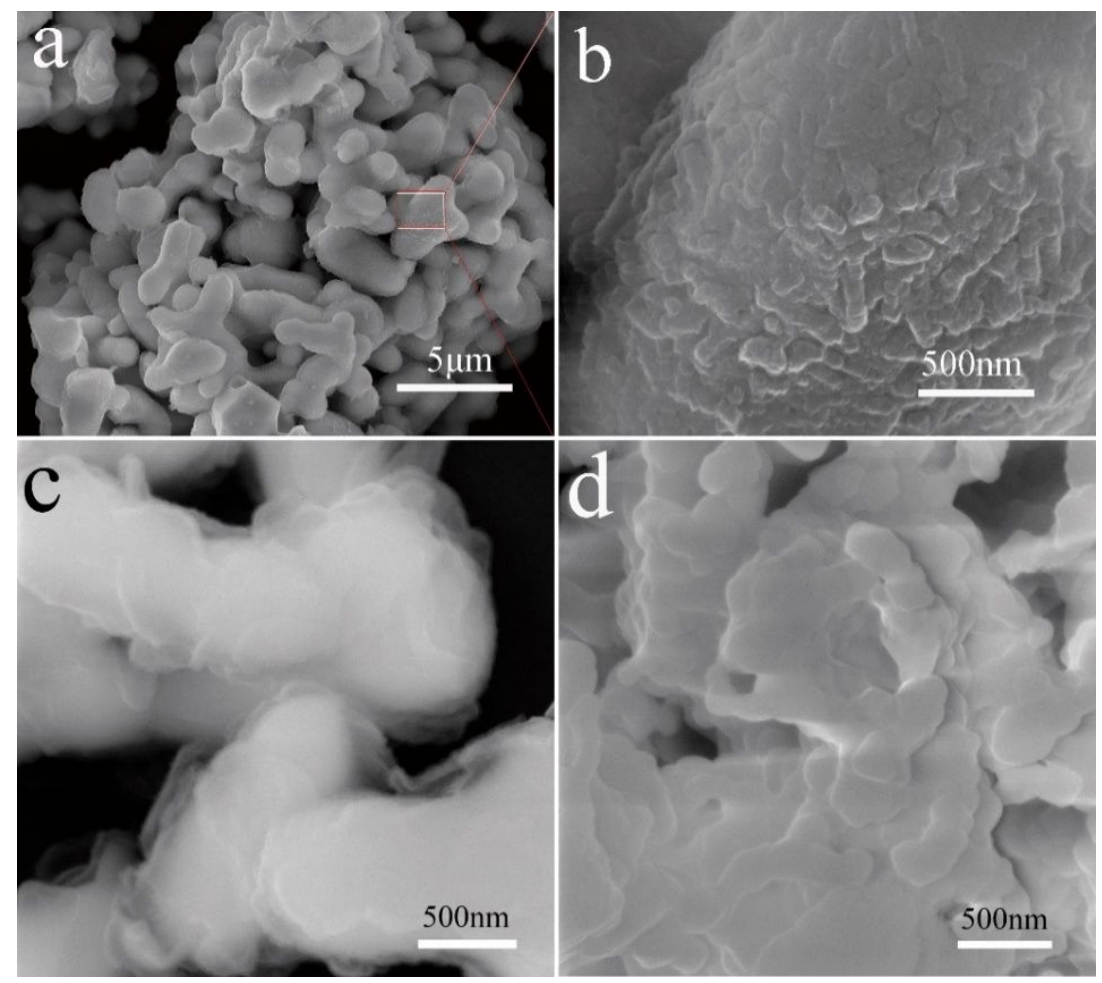

Figure S1 SEM of LLZO-P (a) and partial enlarged view of LLZO-P (b), LLZO-S (c) and LLZO-

$\mathrm{B}(\mathrm{d})$

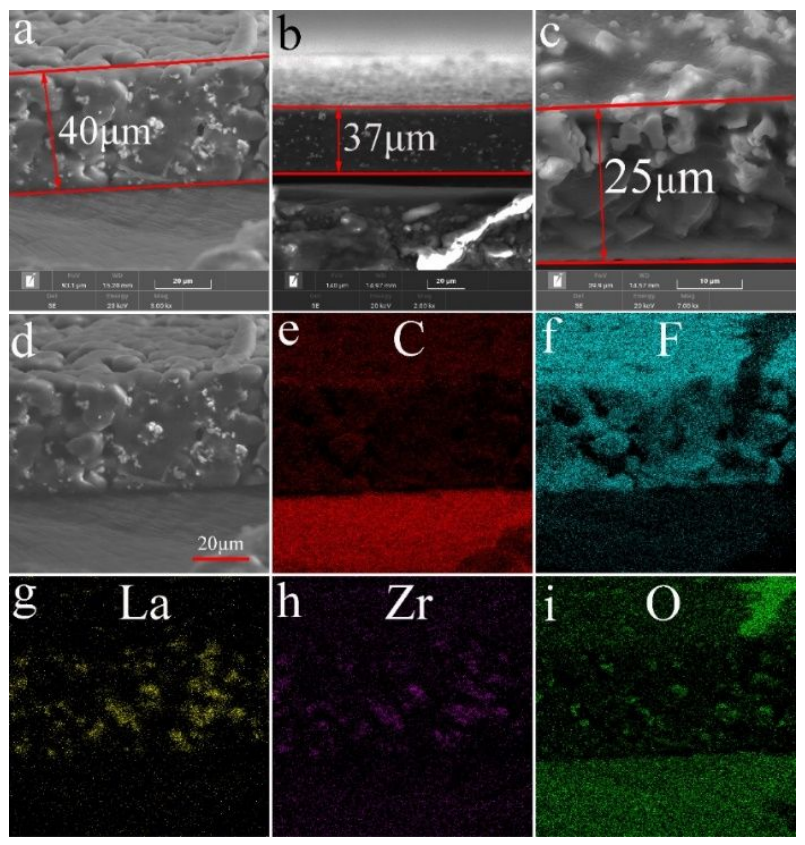


Figure S2 SEM images of the cross-section in PLLP (a, d), PLLS (b), PLLB (c) and the element mapping for C (e), F (f), La (g), Zr (h) and O (i) of PLLP

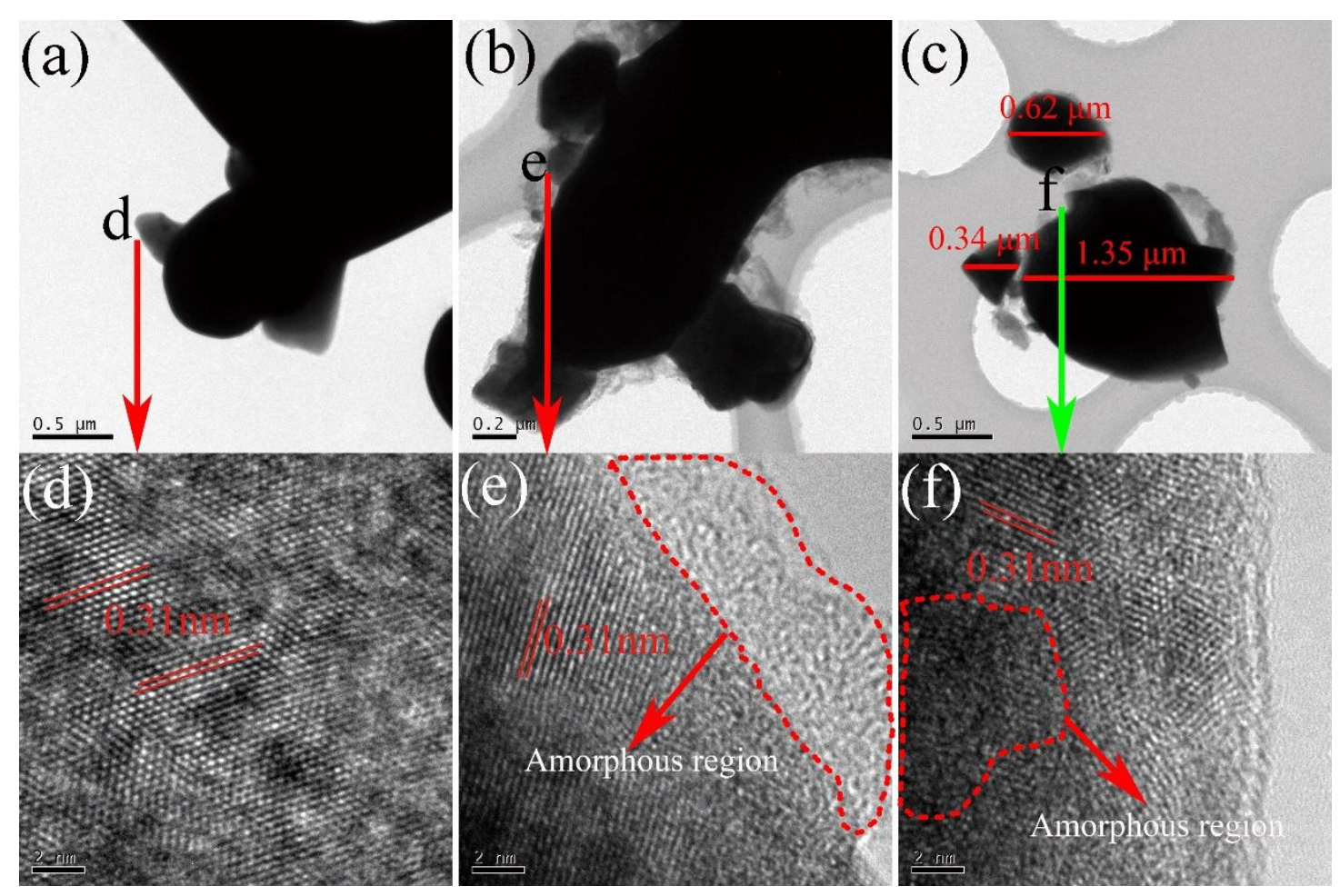

Figure S3 HR-TEM images of samples: LLZO-P(a, d), LLZO-S(b, e), and LLZO-B(c, f) 

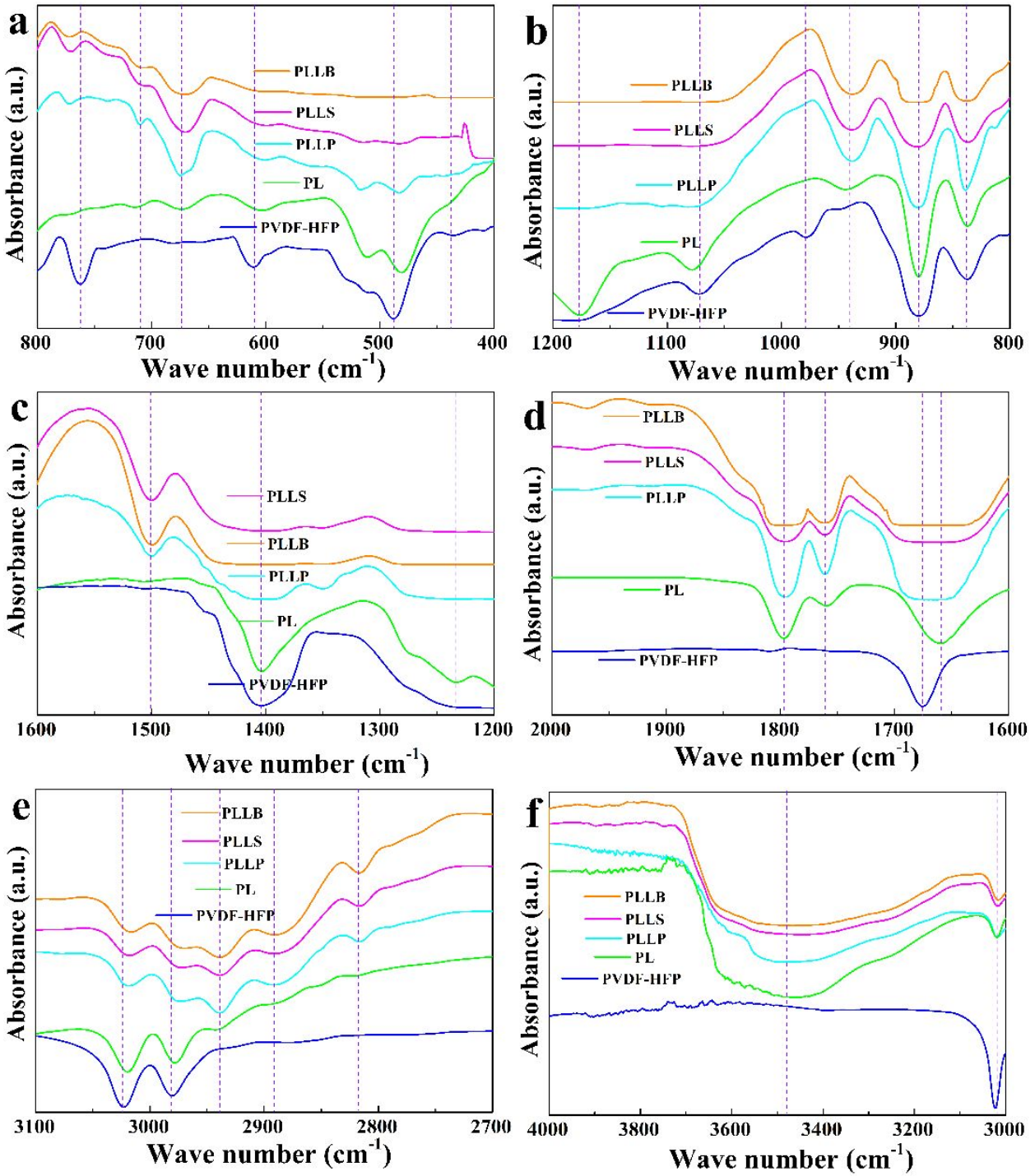

Figure S4 FT-IR of PVDF-HFP, PL and CSEs at different wave number 

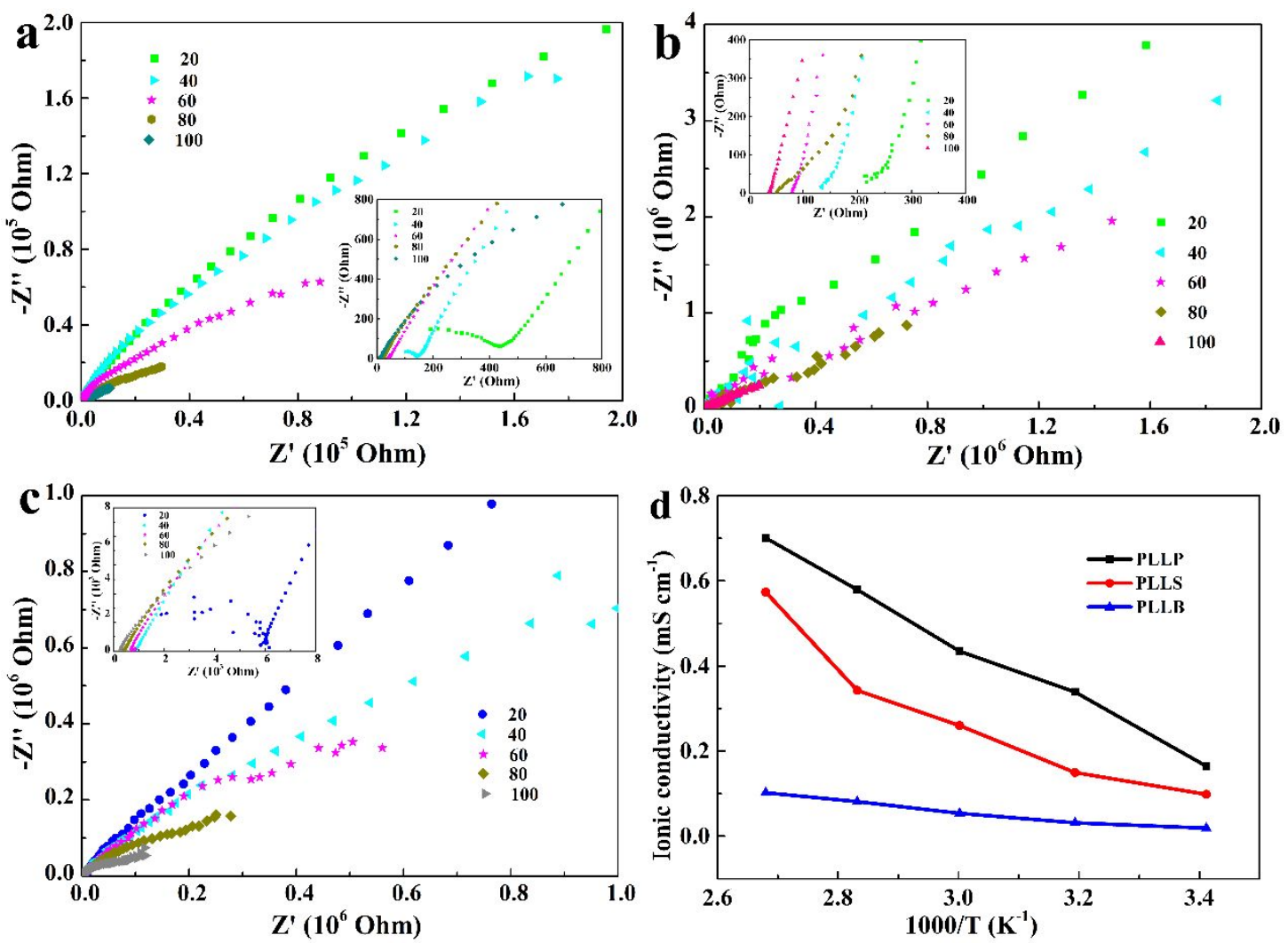

Figure S5 Nyquist plots of the SS/PPLP/SS (a), SS/PPLS/SS (b) and SS/PPLB/SS cell (c) and ionic conductivity of PPLP, PPLS, PPLB 

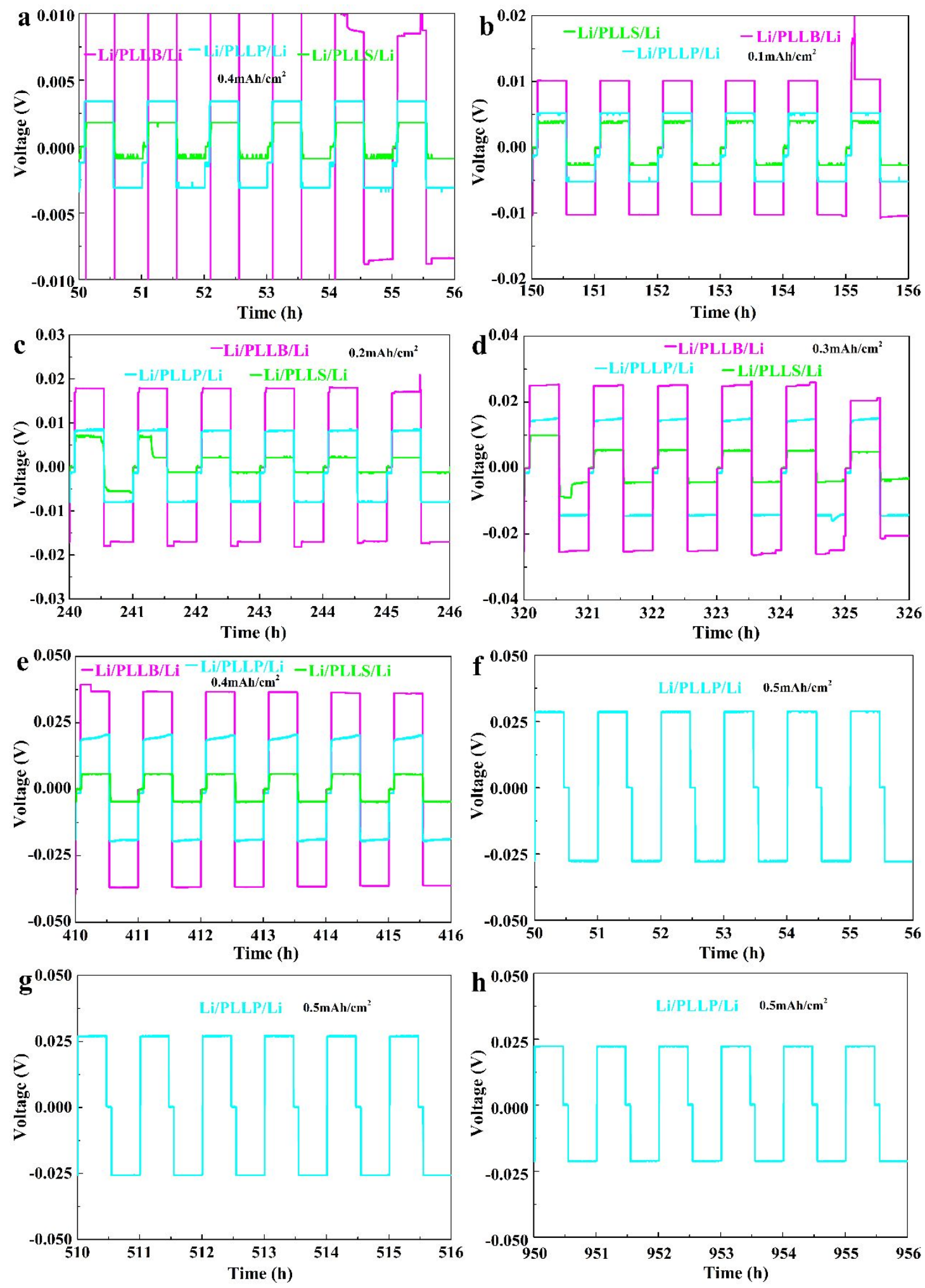

Figure S6 The enlarged view of voltage-time curves in $\mathrm{Li} / / \mathrm{Li}$ cells 

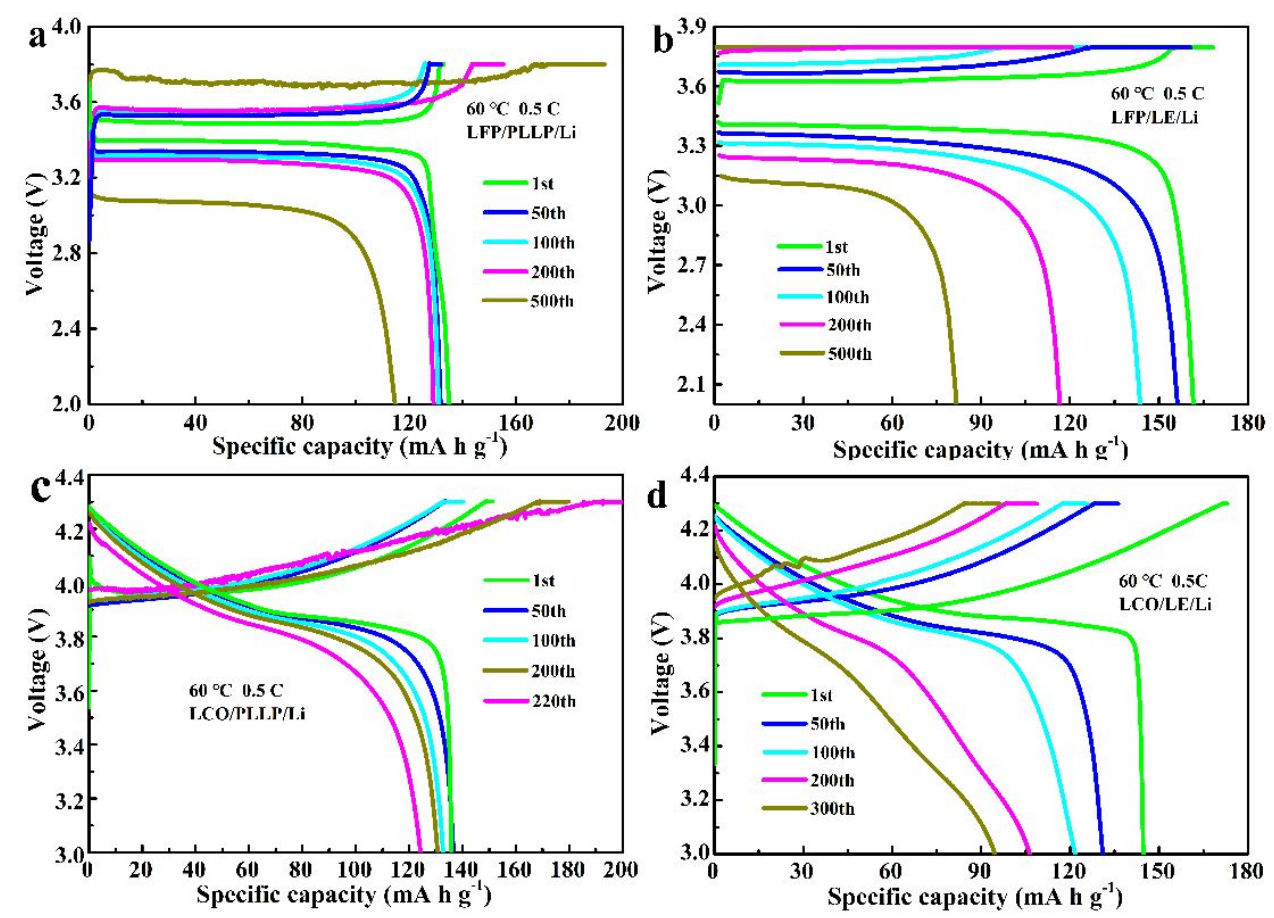

Figure S7 The charge and discharge curves of LFP/PLLP/Li (a), LFP/LE/Li (b), LCO/PLLP/Li (c) and $\mathrm{LCO} / \mathrm{LE} / \mathrm{Li}(\mathrm{d})$ cells at $1^{\text {st }}, 50^{\text {th }}, 100^{\text {th }}, 200^{\text {th }}, 220^{\text {th }}, 300^{\text {th }}$ and $500^{\text {th }}$ cycles
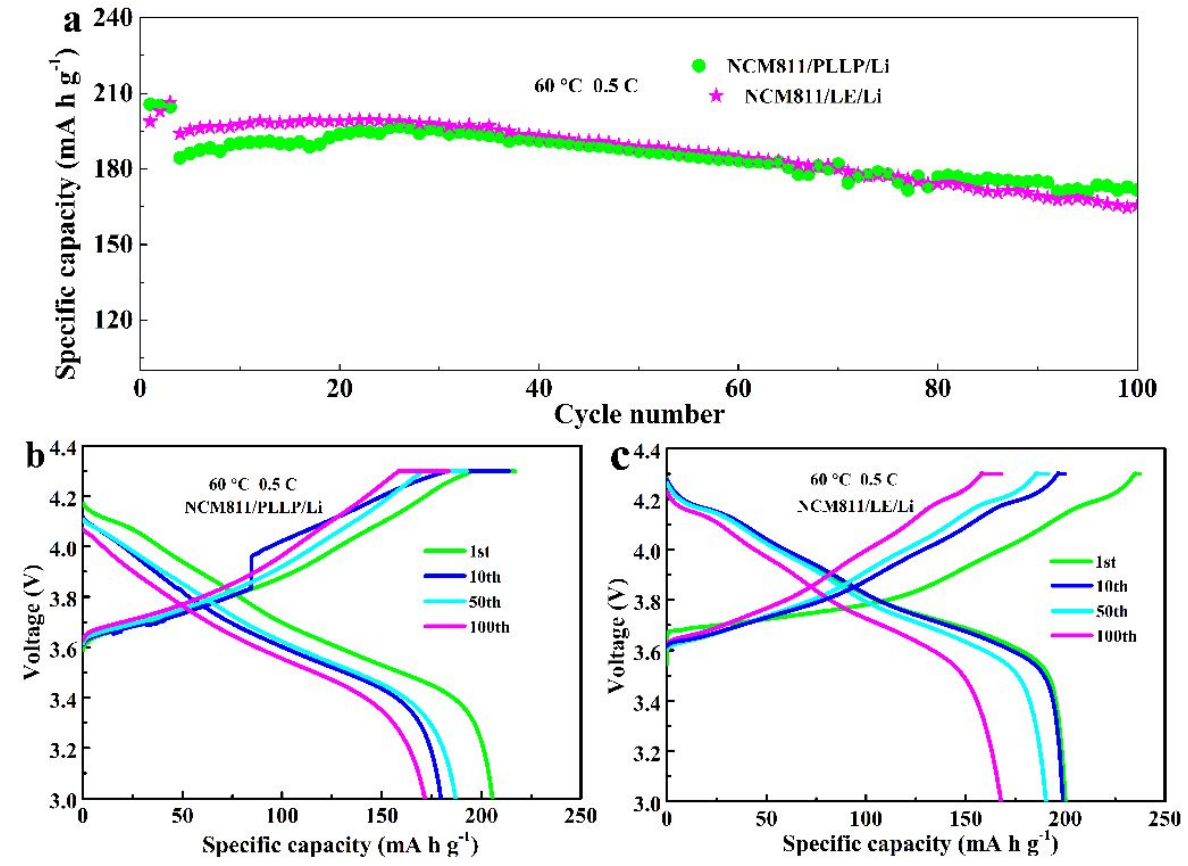

Figure S8 The long-term cycling performances (a) of the NCM811//Li cells with PLLP and liquid electrolyte at $60^{\circ} \mathrm{C}, 0.5 \mathrm{C}$ discharge rate; The charge and discharge curves of NCM811/PLLP/Li (b) and NCM811/LE/Li (c) cells at $1^{\text {st }}, 10^{\text {th }}, 50^{\text {th }}, 100^{\text {th }}, 200^{\text {th }}$, and $500^{\text {th }}$ cycles 


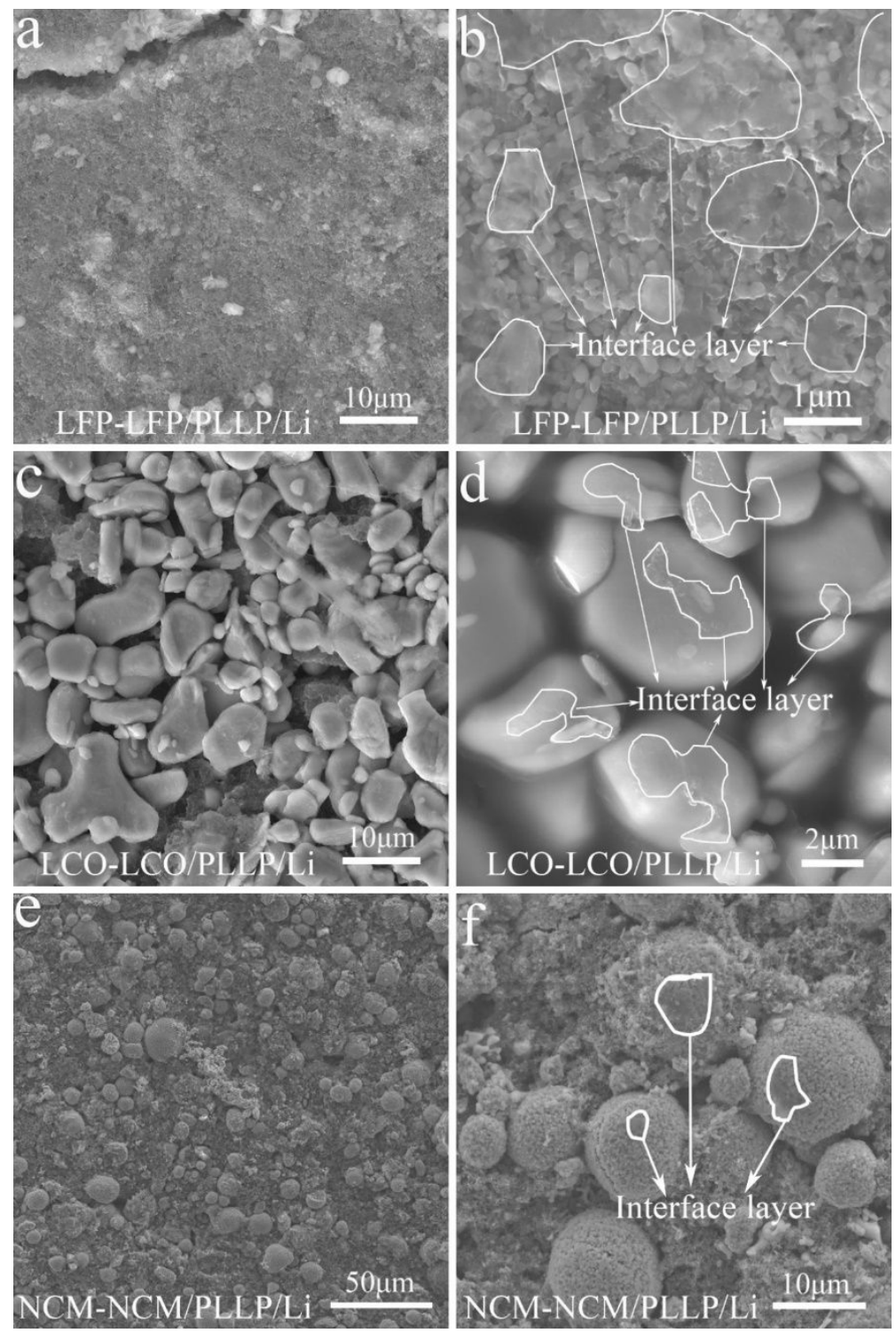

Figure S9 The SEM of LFP (a,b), LCO (c,d) and NCM811 (e,f) in SLBs after 500, 227 and 100 cycles 


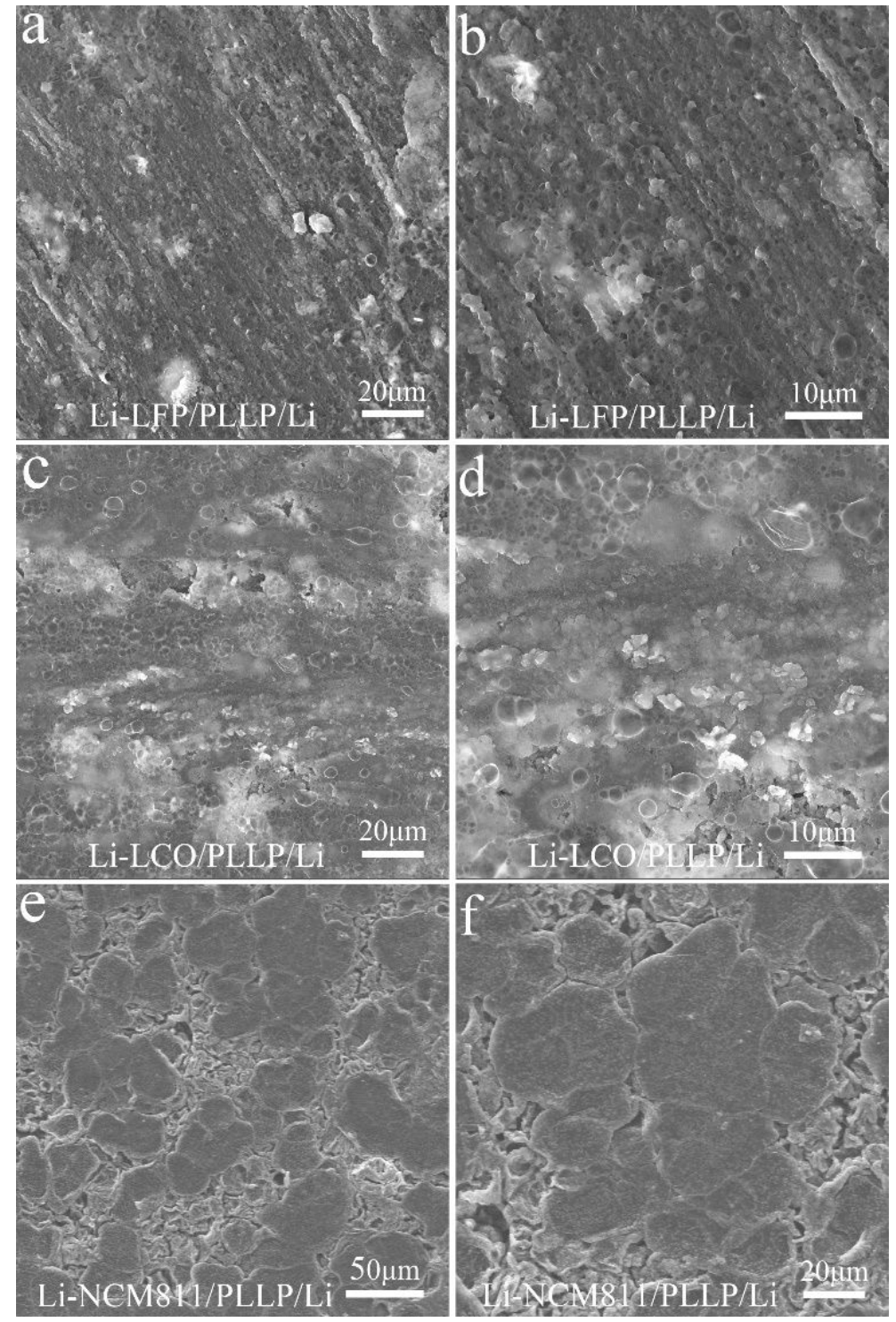

Figure S10 SEM of Li film in LFP (a-b), LCO (c-d) and NCM811 (e-f) SLBs after 500, 227 and 100 cycles
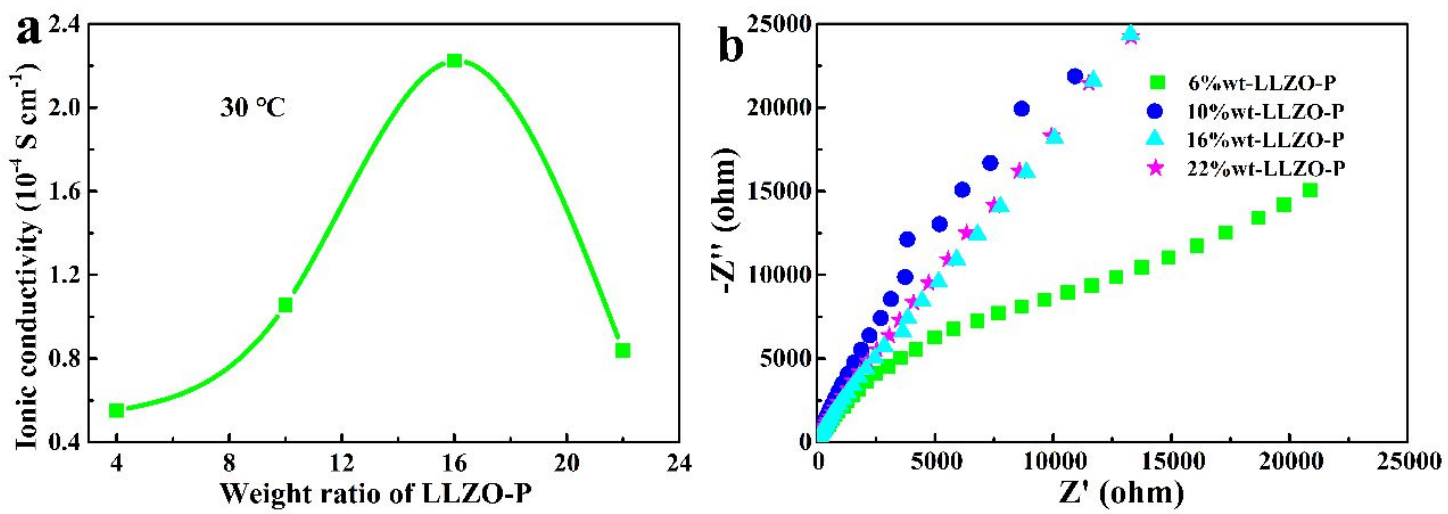

Figure S11 The ionic conductivity and Nyquist curve of PLLP with different weight ratio of 

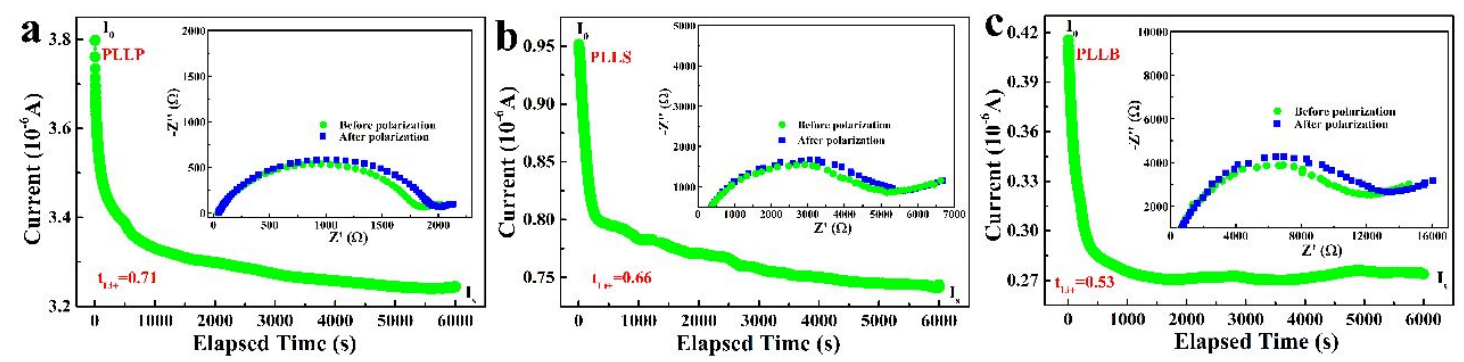

Figure S12 The lithium ion migration number of PLLP (a), PLLS (b) and PLLB(c)

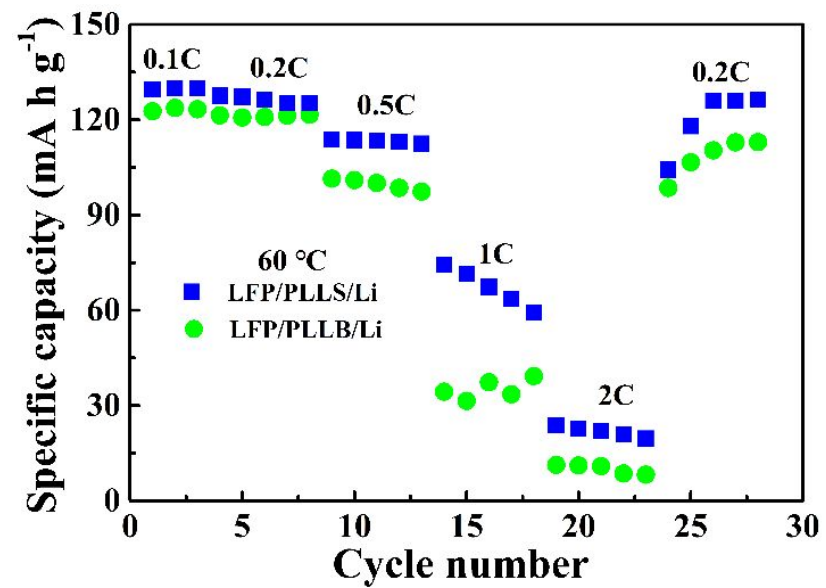

Figure S13 The C-rate performance of $\mathrm{LiFePO}_{4}$ battery with PLLB and PLLS

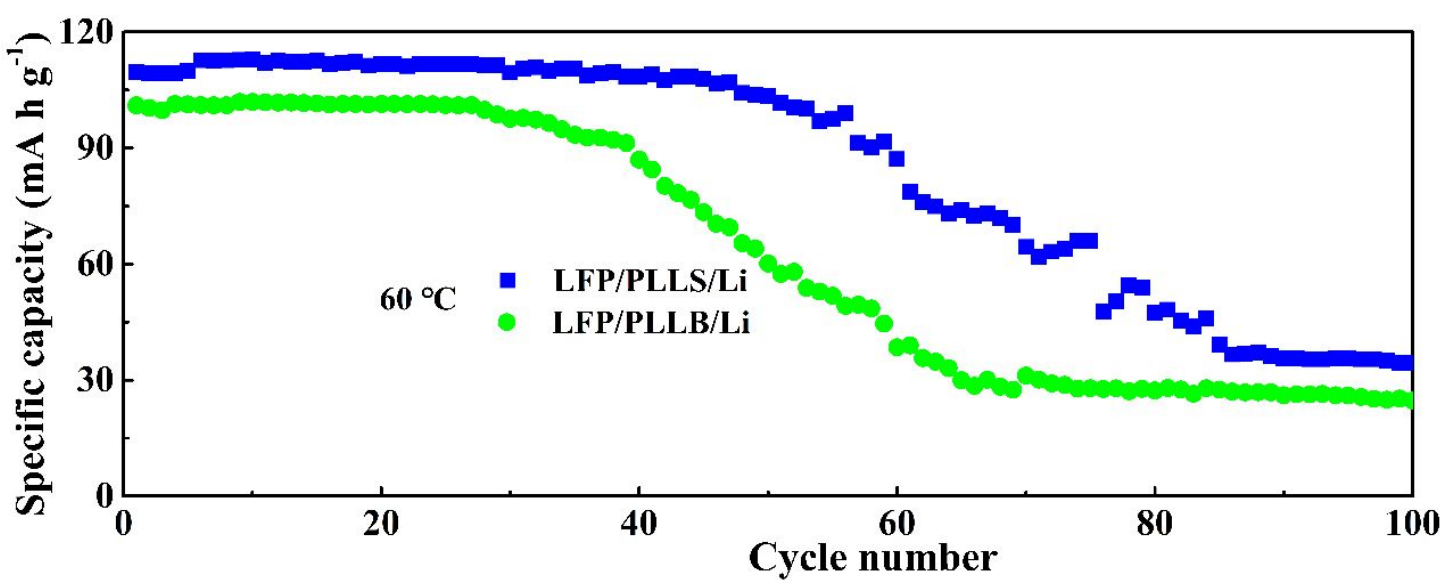

Figure S14 The cycle performance of $\mathrm{LiFePO}_{4}$ battery with PLLB and PLLS 